\title{
Development of a mathematical model for alkylation of $m$-cresol with $\alpha$-methylstyrene using anhydrous aluminium chloride
}

\author{
S. Sultana ${ }^{1}$, A. S. M. S. Arefin ${ }^{2}$ and M. Shahruzzaman ${ }^{3 *}$ \\ ${ }^{I}$ Department of Arts and Sciences, Ahsanullah University of Science and Technology, 141 \& 142, Love road, Dhaka-1208, \\ Bangladesh \\ ${ }^{2}$ Department of Biomedical Physics and Technology, University of Dhaka, Dhaka-1000, Bangladesh \\ ${ }^{3}$ Department of Applied Chemistry and Chemical Engineering, University of Dhaka, Dhaka-1000, Bangladesh
}

Received: 07 June 2018

Revised: 29 October 2018

Accepted: 06 May 2019

DOI: $10.3329 /$ bjsir.v54i3.42671

\begin{abstract}
Alkylaromatic compounds such as alkylphenols are the most wide spread and efficient material due to its broad practical utilization in different arenas including antioxidants, stabilizers for fuels, lubricating oils, polymeric materials and so on. In this work, (2-phenylpropan-2-yl) $m$-cresol with high yield was prepared from the reaction between $m$-cresol and a-methylstyrene in the presence of anhydrous aluminium chloride catalyst. Plackett-Burman design was applied for screening significant variables, such as, temperature, molar ratio of $m$-cresol to a-methylstyrene, time of reaction and amount of catalyst etc. to determine an optimum condition for the production of (2-phenylpropan-2-yl) $m$-cresol. Moreover, a $2^{3}$ Yates pattern factorial design was used to develop a mathematical model to predict the yield of alkylation of $m$-cresol with a-methylstyrene. Analyses of the results revealed that temperature, molar ratio and amount of catalyst were the main effective variables. The products were characterized by FT-IR, UV-visible and ${ }^{1} \mathrm{H}$ NMR spectroscopy. The adequacy of the suggested model was checked up. The experimental yields exhibited good agreement with the predicted yields designed by the mathematical model. Hence, (2-phenylpropan-2-yl) $m$-cresol has the potential to be used as an industrially important compound in various applications.
\end{abstract}

Keywords: $m$-Cresol; $\alpha$-Methylstyrene; Anhydrous aluminium chloride; Catalyst

\section{Introduction}

Owing to the practical importance of alkylaryl compounds, alkylation process has earned much importance and attention of the scientists since its invention. Among them, alkyl phenols and their derivatives demonstrate outstanding antioxidant and multifunctional stabilizing properties (Shahruzzaman et al., 2015; Lebedev, 1984; Alam et al., 2015). Use of antioxidants has become increasingly important to protect synthetic fuels, lubricating oils and polymeric materials against thermal degradation due to heat, light, air, oxygen, ozone etc. In addition, some of their derivatives are strong herbicides and bactericides (Melinikov et al., 1954; Nemetkin et al., 1951). Furthermore, alkylated cresols with long alkyl group are intermediates for surfactants and detergents (Shahruzzaman et al., 2015; Dritriev et al., 1961). Among the alkylation processes, alkylation of cresols is very important.
Alkylaryl compounds are usually obtained by alkylation of hydrocarbons, halobenzenes and phenols with alcohols, olefins and alkylhalides in the presence of several different catalysts. Consequently, isomeric cresols have been alkylated by olefins in the presence of several different acidic catalysts (Saha et al., 2003, 2005, 2008, 2000, Saha et al., 2006; Starkov et al., 1972; Yadav and Pala, 2000; Palma et al., 2007; Bhuiyan et al., 2005). However, no attempt has so far been made to study the reaction of $m$-cresol with a-methylstyrene in the presence of anhydrous aluminium chloride.

In this context, the objective of this research work was to synthesize and develop a mathematical model for the reaction of $m$-cresol with a-methylstyrene in the presence of

*Corresponding author e-mail: shahruzzaman@du.ac.bd 
anhydrous aluminium chloride as catalyst. The remainder of the article discusses the materials and methods, results and discussions and finally summarizes the overall research findings in subsequent sections.

\section{Materials and methods}

\section{Materials}

The chemicals used in this research work were of reagent grade. $m$-Cresol and anhydrous aluminium chloride were purchased from Sigma-Aldrich (Tokyo, Japan). a-methylstyrene was purchased from Wako Chemicals (Tokyo, Japan). Toluene was obtained from Nacalai tesque (Kyoto, Japan). Water was purified using Milli-Q water purification system (Millipore, Japan).

\section{Methods}

The reactions were carried out in a three necked round-bottomed flask fitted with a condenser, a thermometer, a dropping funnel and a stirrer. $m$-Cresol and catalyst mixture was charged into the flask, heated to the temperature of the experiment, then a-methylstyrene was introduced into the mixture gradually over a certain period (addition time) with constant stirring. The reaction mixture was stirred for another period (stirring time) at the same temperature after the addition of the total amount of a-methylstyrene. The reaction mass was then cooled to room temperature, dissolved in toluene and neutralized. The reaction mixture was then washed with distilled water several times and unreacted reactants and solvent were distilled off at atmospheric pressure. The residual product was finally distilled and characterized by spectral and physico-chemical means.A simple technological flow diagram for the whole reaction procedure is shown in Fig. 1.

The mathematical modeling was performed using Yates pattern experimental design (Clausen and Matson, 1978). The experimental design used was a 3 factor two-level factorial, i.e., there were $2^{3}$ or eight trials. Since the basic $2^{3}$ factorial design involved eight trials, each was run in

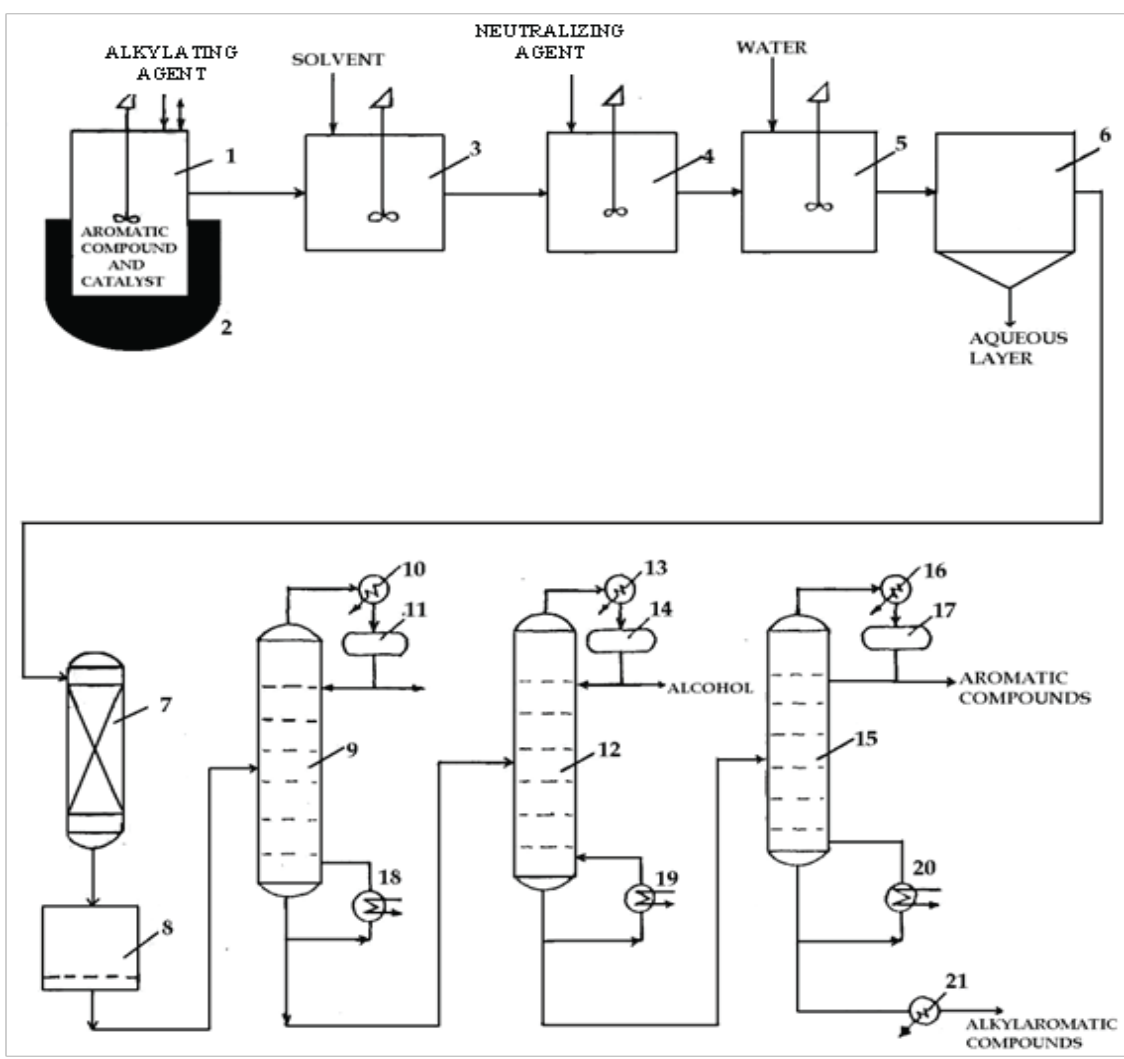

Fig. 1. Technological flow diagram for the alkylation of aromatic compounds (2- Reactor, 3- Heating system, 4- Solvent mixture, 5- Neutralization tank, 6- Washing tank, 7- Separator, 8- Filter, 9,12,15- Atmospheric distillation column, 10,13,16- Condensers, 11,14,17- Receivers, 18,19,20- Boilers, 21- Cooler) 
duplicate yielding 16 trials. In order to check the lack of fit due to curvature, additional trial was made at the midpoint level of each factor. The difference between the average center point value and the overall average of the design points indicated the severity of curvature.

The average yield $\mathrm{Y}$, the range, and the variance were calculated for each trial. The variance, which is an estimate of dispersion of data, was calculated by the following formula:

Variance $=S^{2}=\frac{\left(Y_{1}-\bar{Y}\right)^{2}+\left(Y_{2}-\bar{Y}\right)^{2}+\ldots \ldots \ldots \ldots+\left(Y_{n}-\bar{Y}\right)^{n}}{n-1}$

where, $\mathrm{Y}=$ response value, $\mathrm{Y}=$ average or mean of response values and $\mathrm{n}=$ number of observations.

The variances calculated for each trial were then used in the calculation of a weighted average of the individual variances for each trial.

Pooled variance $=\mathrm{S}_{\text {pooled }}^{2}=\frac{\left(\mathrm{n}_{1}-1\right)\left(\mathrm{S}_{1}{ }^{2}\right)+\left(\mathrm{n}_{2}-1\right)\left(\mathrm{S}_{2}{ }^{2}\right)+\ldots \ldots \ldots \ldots \ldots+\left(\mathrm{n}_{\mathrm{k}}-1\right)\left(\mathrm{S}_{\mathrm{k}}{ }^{2}\right)}{\left(\mathrm{n}_{1}-1\right)+\left(\mathrm{n}_{2}-1\right)+\ldots \ldots \ldots \ldots \ldots \ldots \ldots+\left(\mathrm{n}_{\mathrm{k}}-1\right)}$

After that the pooled standard deviation was calculated which is the square root of the pooled variance:

Standard deviation $_{\text {pooled }}=\sqrt{ } \mathrm{S}_{\text {pooled. }}^{2}$

Following the calculations, the computational analysis matrix was developed to detect any interaction effect. This computation matrix was generated by simple algebraic multiplication of the coded factor levels.

Next the minimum significant factor effect [MIN] and the minimum significant curvature effect [MIN C] were derived from t-test significance criteria. The relationships are:

$$
\begin{gathered}
{[\mathrm{MIN}]=\mathrm{t} . \mathrm{S} \sqrt{\frac{2}{m \cdot k}}} \\
{[\mathrm{MIN} \mathrm{C}]=\mathrm{t} . \mathrm{S} \sqrt{\frac{1}{m \cdot k}+\frac{1}{c}}}
\end{gathered}
$$

Where, $\mathrm{t}=$ appropriate value from " $\mathrm{t}$ table", $\mathrm{S}=$ pooled standard deviation, $m=$ number of plus signs in the column, $k=$ number of replicates in each trial and $c=$ number of centre points.

All the derived values were put in to the mathematical model to develop a first order polynomial equation. Finally, the product was studied via NMR for further analysis.

\section{Results and discussion}

$m$-Cresol with a-methylstyrene in the presence of anhydrous aluminium chloride gave (2-phenylpropan-2-yl) $m$-cresol. Three parameters viz. temperature, molar ratio of $m$-cresol to a-methylstyrene, amount of anhydrous aluminium chloride were considered in the development of the mathematical model of the reaction of $m$-cresol with a-methylstyrene in the presence of anhydrous aluminium chloride using Yates pattern. The experimental ranges of the variables are listed in Table I. The critical response of interest was the yield of (2-phenylpropan-2-yl) $m$-cresol. Addition time of a-methylstyrene to $m$-cresol and anhydrous aluminium chloride mixture was $2 \mathrm{~h}$ and time of stirring after the addition of indene was $1 \mathrm{~h}$.

Table I. Process variables and response

\begin{tabular}{lccc}
\hline Variables & \multicolumn{3}{c}{ Range } \\
& $\begin{array}{r}\text { Low } \\
(-)\end{array}$ & $\begin{array}{r}\text { Mid } \\
(0)\end{array}$ & $\begin{array}{c}\text { High } \\
(+)\end{array}$ \\
\hline $\mathrm{X}_{1}$ Temperature $\left({ }^{\circ} \mathrm{C}\right)$ & 70 & 100 & 130 \\
$\mathrm{X}_{2,}$ Molar ratio of $m$-cresol to a-methylstyrene & $4: 1$ & $6: 1$ & $8: 1$ \\
$\mathrm{X}_{3,}$ Amount of catalyst, \% by wt. of $m$-cresol & 3 & 5.5 & 8 \\
\hline Y, Response: \% yield of (2-phenylpropan-2-yl) $m$-cresol
\end{tabular}

Table II illustrates the two-level 3 factor design with the factors in coded form. The experimental runs for trial 1 through 8 were run in duplicate; trial 9 , the centre point trial was run four times, interspersed throughout the experimental runs.

\begin{tabular}{|c|c|c|c|c|}
\hline \multirow{2}{*}{$\begin{array}{c}\text { Trial } \\
\text { No. }\end{array}$} & \multirow[t]{2}{*}{ Replicates } & \multicolumn{3}{|c|}{ Design } \\
\hline & & $\begin{array}{c}\text { Temperature, } \\
\mathrm{x}_{1}\end{array}$ & $\begin{array}{c}\text { Molar ratio, } \\
\mathrm{x}_{2}\end{array}$ & $\begin{array}{l}\text { Amount of } \\
\text { catalyst, } x_{3}\end{array}$ \\
\hline 1 & 2 & - & - & - \\
\hline 2 & 2 & + & - & - \\
\hline 3 & 2 & - & + & - \\
\hline 4 & 2 & + & + & - \\
\hline 5 & 2 & - & - & + \\
\hline 6 & 2 & + & - & + \\
\hline 7 & 2 & - & + & + \\
\hline 8 & 2 & + & + & + \\
\hline 9 & 4 & 0 & 0 & 0 \\
\hline
\end{tabular}

\section{Table II. Experimental design}


The results of these experiments are listed in Table III. Each measured value of yield was listed.

Table III. Results of 3 factor experiment

\begin{tabular}{|c|c|c|c|c|c|}
\hline \multirow[t]{3}{*}{ Trial No. } & \multicolumn{5}{|c|}{ Results } \\
\hline & \multicolumn{3}{|c|}{ Yield } & \multirow[t]{2}{*}{ Range } & \multirow[t]{2}{*}{ Variance } \\
\hline & $\mathrm{Y}_{1}$ & $\mathrm{Y}_{2}$ & $\mathrm{Y}$ & & \\
\hline 1 & 39.8 & 40.6 & 40.2 & 1 & 0.32 \\
\hline 2 & 66.4 & 67.6 & 67.0 & 2 & 0.72 \\
\hline 3 & 50.7 & 51.7 & 51.2 & 1 & 0.50 \\
\hline 4 & 77.0 & 78.8 & 77.9 & 2 & 1.62 \\
\hline 5 & 54.4 & 55.6 & 55.0 & 1 & 0.72 \\
\hline 6 & 78.9 & 80.7 & 79.8 & 2 & 1.62 \\
\hline 7 & 63.4 & 65.0 & 64.2 & 2 & 1.28 \\
\hline 8 & 93.6 & 95.8 & 94.7 & 2 & 2.42 \\
\hline 9 & 66.2 & & & & \\
\hline 66.7 & 67.5 & & & & \\
\hline 68.0 & 67.1 & 2 & 0.65 & & \\
\hline
\end{tabular}

\section{Calculation of Variance}

For example, for trial 1 ,

variance, $\mathrm{S}_{1}{ }^{2}=\frac{(39.8-40.2)^{2}+(40.6-40.2)^{2}}{2-1}=0.32$

and for trial 9,

variance, $\mathrm{S}_{9}{ }^{2}=\frac{(66.2-67.1)^{2}+(67.5-67.1)^{2}+(66.7-67.1)^{2}+(68.0-67.1)^{2}}{4-1}=0.65$

\section{Calculation of weighted average and standard deviation}

Pooled variance $=\mathrm{S}_{\text {pooled }}^{2}$

$=\frac{1(0.32)+1(0.72)+1(0.50)+1(1.62)+1(0.72)+1(1.62)+1(1.28)+1(2.42)+3(0.65)}{1+1+1+1+1+1+1+1+3}$

$=(9.2+1.95) / 11=1.01364$

Standard deviation $_{\text {pooled }}=\sqrt{ } 1.01364$

$$
=1.0068
$$

The pooled standard deviation was used to calculate the minimum observed effect that was statistically significant.

\section{Construction of the mathematical model}

The computational analysis for this experiment is shown in Table IV. In Trial $1, \mathrm{x}_{1}$ was minus, $\mathrm{x}_{2}$ was minus, therefore $\mathrm{x}_{1} \mathrm{x}_{2}$ was plus; in Trial 2, $x_{1}$ was plus, $x_{2}$ was minus, therefore, $x_{1} x_{2}$ was minus. The column at the far right of the table is the average yield for each trial. The sum +'s row was generated by totaling the response values on each row with a plus for each column.For $\mathrm{x}_{1}$ factor, $67.0+77.9+79.8+94.7=319.4$. In the similar manner the sum -'s row was generated. The sum of these two rows should equal the sum of all the average responses and was included as a check on the calculations. The difference row represented the difference between the responses in the four trials when the factor was at a high level and the responses in the four trials when the factor was at a low level. The effect was calculated by dividing the difference by the number of plus signs in the column. In the first column, labeled mean, the effect row value was the mean or average of all data points. The average of the centre point runs, Trial 9, was subtracted from the mean effect to give a measure of curvature.

The $t$ value of 2.20 was from the students " $t$ " table for the 95\% confidence level and 11 degrees of freedom (Davies 1979). The degrees of freedom resulted from eight trials with two replicates and one trial with four replicates.

Degrees of freedom $=8(2-1)+1(4-1)=11$

The calculation for the minimum significant effects was as follows,

$[\mathrm{MIN}]=2.20 \times 1.0068 \times \sqrt{\frac{2}{4 \times 2}}=1.10748$

$[\mathrm{MIN} \mathrm{C}]=2.20 \times 1.0068 \times \sqrt{\frac{1}{8 \times 2}+\frac{1}{4}}=1.2382$

Applying these criteria to the calculated effects, it was seen that the effects of temperature $\left(\mathrm{x}_{1}\right)$, molar ratio of $m$-cresol to a-methylstyrene $\left(x_{2}\right)$, amount of anhydrous aluminium chloride $\left(\mathrm{x}_{3}\right)$ were significant. The effects were also significant in the interactions between temperature and molar ratio of $m$-cresol to a-methylstyrene $\left(\mathrm{x}_{1} \mathrm{x}_{2}\right)$, and in the interactions among temperature, molar ratio of $m$-cresol to a-methylstyrene and amount of anhydrous aluminium chloride. There was no significant curvature effect. The values for the co-efficients were one half the factor effects listed in Table IV. Since these were based upon coded levels +1 and -1 that differed by two units.

$Y=66.25+13.6 x_{1}+5.75 x_{2}+7.175 x_{3}+0.7 x_{1} x_{2}+0.725 x_{1} x_{2} x_{3}$

In this equation the factors were expressed in coded units. These were converted into real units by substituting: 
Table IV. Computation matrix for three factor experiment

\begin{tabular}{|c|c|c|c|c|c|c|c|c|c|}
\hline \multirow{3}{*}{$\begin{array}{c}\text { Trial } \\
\text { No. }\end{array}$} & \multirow{3}{*}{$\begin{array}{c}\text { Mean } \\
.\end{array}$} & \multicolumn{3}{|c|}{ Design } & \multicolumn{4}{|c|}{ Computation } & \multirow{3}{*}{$\begin{array}{c}\text { Response } \\
\mathrm{Y}\end{array}$} \\
\hline & & . & . & . &. & . & . & . & \\
\hline & & $\mathrm{x}_{1}$ & $\mathrm{x}_{2}$ & $\mathrm{x}_{3}$ & $\mathrm{x}_{1} \mathrm{x}_{2}$ & $\mathrm{x}_{1} \mathrm{x}_{3}$ & $\mathrm{x}_{2} \mathrm{x}_{3}$ & $\mathrm{x}_{1} \mathrm{x}_{2} \mathrm{x}_{3}$ & \\
\hline$\overline{1}$ & + & - & - & - & + & + & + & - & 40.2 \\
\hline 2 & + & + & - & - & - & - & + & + & 67.0 \\
\hline 3 & + & - & + & - & - & + & - & + & 51.2 \\
\hline 4 & + & + & + & - & + & - & - & - & 77.9 \\
\hline 5 & + & - & - & + & + & - & - & + & 55.0 \\
\hline 6 & + & + & - & + & - & + & - & - & 79.8 \\
\hline 7 & + & - & + & + & - & - & + & - & 64.2 \\
\hline 8 & + & + & + & + & + & + & + & + & 94.7 \\
\hline Sum '+'s & 530 & 319.4 & 288 & 293.7 & 267.8 & 265.9 & 266.1 & 267.9 & \\
\hline \multicolumn{10}{|l|}{ Sum } \\
\hline '-' s & 0.0 & 210.6 & 242 & 236.3 & 262.2 & 264.1 & 263.9 & 262.1 & \\
\hline Sum & 530 & 530 & 530 & 530 & 530 & 530 & 530 & 530 & \\
\hline Differe-nce & 530 & 108.8 & 46 & 57.4 & 5.6 & 1.8 & 2.2 & 5.8 & \\
\hline Effect & 66.25 & $27.2 *$ & $11.5^{*}$ & $14.35^{*}$ & $1.4^{*}$ & 0.45 & 0.55 & 1.45 & \\
\hline
\end{tabular}

* Curvature $=66.25-67.1=-0.85$

Table V. Experimental average yield and calculated yield of (2-phenylpropan-2-yl) $m$-cresol

\begin{tabular}{lcccc}
\hline Trial No. & $\mathrm{Y}_{\text {(exp.) }}$ & $\mathrm{Y}_{\text {(calc) }}$ & Deviation & Percentage deviation \\
\hline 1 & 40.20 & 39.70 & 0.50 & 1.24 \\
2 & 67.00 & 66.90 & 0.10 & 0.15 \\
3 & 51.20 & 51.10 & 0.10 & 0.19 \\
4 & 77.90 & 78.40 & -0.50 & -0.64 \\
5 & 55.00 & 55.50 & -0.50 & -0.90 \\
6 & 79.80 & 79.85 & -0.05 & -0.06 \\
7 & 64.20 & 64.15 & 0.05 & 0.08 \\
8 & 94.70 & 94.20 & 0.50 & 0.53 \\
\hline
\end{tabular}


for temperature $\left(\mathrm{T}^{0} \mathrm{C}\right), \mathrm{x}_{1}=\frac{\mathrm{T}-(130+70) / 2}{(130-70) / 2}=\frac{\mathrm{T}-100}{30}$

for molar ratio $(m: 1), x_{2}=\frac{m-(8+4) / 2}{(8-4) / 2}=\frac{m-6}{2}$

for the amount of catalyst $(y), x_{3}=\frac{y-(8+3) / 2}{(8-3) / 2}=\frac{y-5.5}{2.5}$

The substitution of $\mathrm{x}_{1}, \mathrm{x}_{2}, \mathrm{x}_{3}$ yielded the following final expression:

$$
\begin{array}{r}
\mathrm{Y}=66.25+13.6 \times\left[\frac{\mathrm{T}-100}{30}\right]+5.75 \times\left[\frac{\mathrm{m}-6}{2}\right]+7.175 \times\left[\frac{\mathrm{y}-5.5}{2.5}\right] \\
+0.7 \times\left[\frac{\mathrm{T}-100}{30}\right]\left[\frac{\mathrm{m}-6}{2}\right]+0.725\left[\frac{\mathrm{T}-100}{30}\right]\left[\frac{\mathrm{m}-6}{2}\right]\left[\frac{\mathrm{y}-5.5}{2.5}\right]
\end{array}
$$

$$
\begin{aligned}
\mathrm{Y}= & -21.065+0.5428 \mathrm{~T}+4.366666 \mathrm{~m}+5.769998 \mathrm{y}- \\
& 0.01491664 \mathrm{Tm}-0.02899998 \mathrm{Ty}- \\
& 0.483333 \mathrm{my}+4.83333 \times 10^{-3} \mathrm{Tmy}
\end{aligned}
$$

For trial 1,

Temperature $(\mathrm{T})=70^{\circ} \mathrm{C}$, molar ratio of $m$-cresol to a-methylstyrene $(\mathrm{m}: 1)=4: 1$ and the amount of catalyst $(\mathrm{y})=$ $3 \%$ by wt. of $m$-cresol.

Therefore, yield calculated from the derived model,

$$
\begin{aligned}
Y_{\text {(calc) }}= & -21.065+37.996+17.466664+17.309994-4.1766592- \\
& 6.0899958-5.799996+4.0599972 \\
= & 39.7
\end{aligned}
$$

Experimental average yield of the trial 1,

$$
\mathrm{Y}_{\text {(expt.) }}=40.2
$$

Hence, deviation

$$
\begin{aligned}
& =(40.20-39.70) \\
& =0.50 \text { and percentage deviation } \\
& =1.24
\end{aligned}
$$

All the values of the experimental average yield and the calculated yield from the derived equation are shown in Table V.
The discrepancies between the experimental and calculated values did not exceed $1.24 \%$.

\section{Spectral Studies}

\section{Fourier Transform Infrared (FT-IR) spectroscopy}

FT-IR measurements were conducted with a JASCO FT/IR-4100 (JASCO, Tokyo, Japan) in the range of 4000-400 $\mathrm{cm}^{-1}$.In the IR-spectrum (Fig. 2) of the product, absorption bands near $810-880 \mathrm{~cm}^{-1}$ showed the presence of 1,2,4-trisubstituted aromatic ring. The presence of $-\mathrm{OH}$ group and aromatic ring was indicated by the bands at $3417 \mathrm{~cm}^{-1}$ and $1500-1600 \mathrm{~cm}^{-1}$, respectively. Bands at $2852 \mathrm{~cm}^{-1}$ and $2922 \mathrm{~cm}^{-1}$ accounted for the saturated $\mathrm{C}-\mathrm{H}$ stretch.

\section{Proton NMR}

${ }^{1} \mathrm{H}$ NMR were recorded by a JEOLJNM-LA400 instrument (JEOL, Tokyo, Japan) at $400 \mathrm{MHz}$ in $\mathrm{CDCl}_{3}$ solutions at 25 ${ }^{\circ} \mathrm{C}$. Chemical shifts $(\delta)$ of ${ }^{1} \mathrm{H}$, expressed in parts per million (ppm) with use of the internal standards $\mathrm{Me}_{4} \mathrm{Si}(\delta=0.00$ ppm). The ${ }^{1} \mathrm{H}$ NMR-spectrum of the product showed signal of the protonsas listed in Table VI.

Table VI. 1H NMR-spectrum of (2-phenylpropan-2-yl) $m$-cresol

\begin{tabular}{lr}
\hline Observed signals of the protons & Chemical shift in the $\delta$ ppm \\
\hline Aromatic ring protons & $7.02-7.72$ \\
-OH group proton & 5.99 \\
All the protons on the indanyl group & $3.15-3.61$ \\
exceptfour on the aromatic ring & $2.49-2.55$ \\
\hline
\end{tabular}

\section{$U V$-visible spectroscopy}

UV/Visible spectroscopic analyses were carried out by V-560 (JASCO, Tokyo, Japan). The UV-spectrum of the product showed strong absorption at $\lambda_{\max }=297.0 \mathrm{~nm}$ in $0.01 \mathrm{M}$ methanol solution.

Furthermore, the boiling point of the prepared (2-phenylpropan-2-yl) $m$-cresol was measured and it was found $287^{\circ} \mathrm{C}$. Also, the refractive index was measured by using refractometer and that was found to be 1.5411 . 


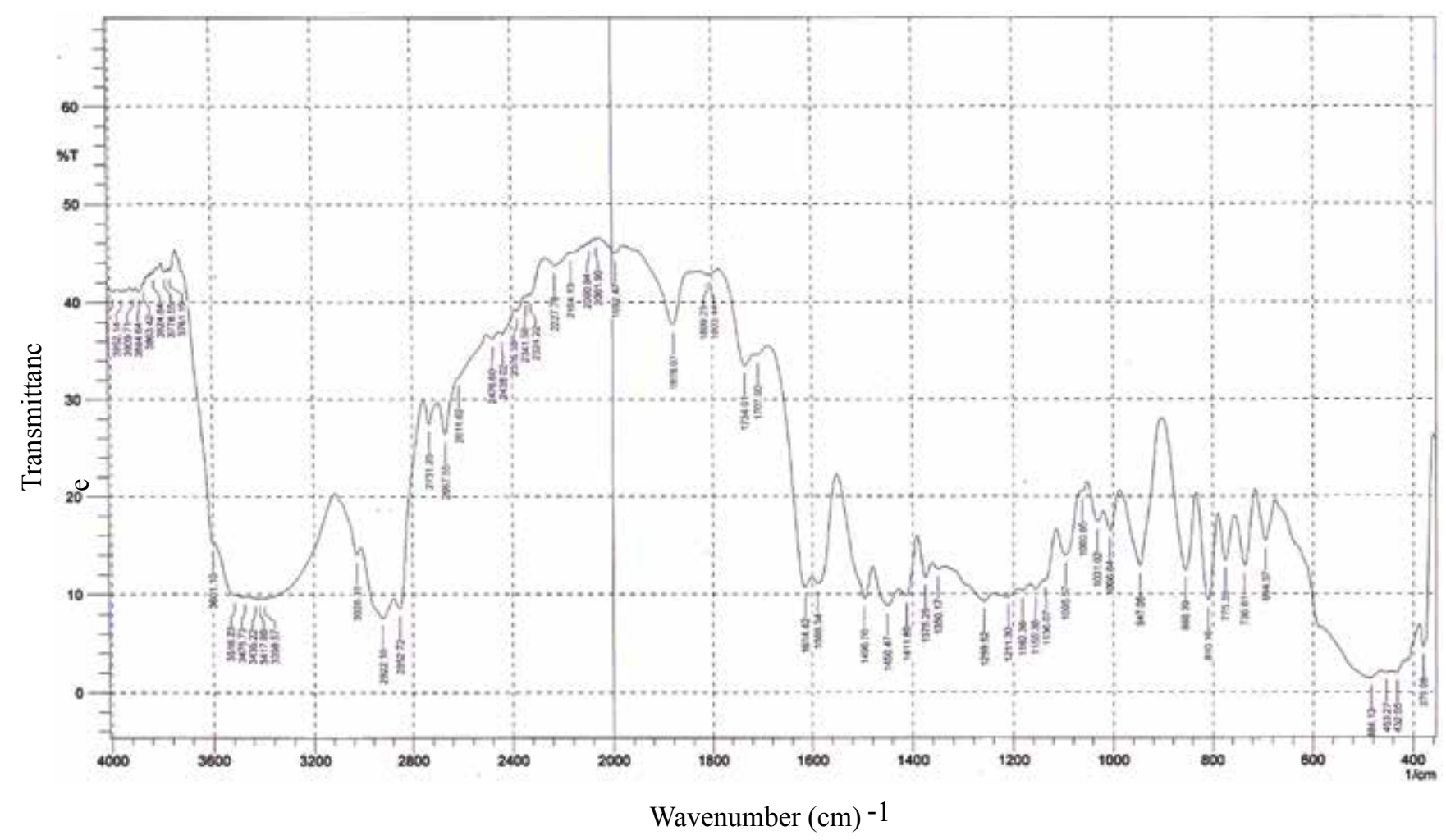

Fig. 2. FT-IR spectra of (2-phenylpropan-2-yl) m-cresol

\section{Conclusion}

An industrially important alkylphenol, (2-phenylpropan2 -yl) $m$-cresol, was synthesized by the alkylation of $m$-cresol with a-methylstyrene in the presence of anhydrous aluminium chloride as catalyst. By means of Plackett-Burman design it was shown that temperature, molar ration of $m$-cresol to a-methylstyrene and amount of catalyst were the significant variables of the reaction. A 23 Yates pattern factorial design gave a mathematical model to predict the yield of the prepared (2-phenylpropan-2-yl) $m$-cresol. The difference between the experimental and predicted yields was negligible. The highest experimentally found yield was $94.7 \%$. The experimental settings were temperature $130^{\circ} \mathrm{C}$, molar ratio of $m$-cresol to a-methylstyrene $8: 1$, amount of catalyst $8 \%$ by wt. of $m$-cresol, addition time $2 \mathrm{~h}$ and stirring time $1 \mathrm{~h}$. The predicted yield was found to be $94.2 \%$. The experimental yield exhibited good agreement with the predicted yield designed by the mathematical model which indicates the power of statistically experimental design methodology. Further investigations will be carried out in future to use (2-phenylpropan-2-yl) $m$-cresol for the manufacture of various types of surfactants and detergents.

\section{References}

Alam MA, Shahruzzaman M, Alam MS and Saha M (2015), Effect of temperature, molar ratio of reactants and amount of catalyst on the yield of alkylation of phenol with benzyl alcohol in the presence of p-toluenesulphonic acid, IJESE 8: 609-612.

Bhuiyan MSI, Hasan MM and Saha M (2005), Reaction of o-cresol with indene, Dhaka Univ. J. Sci. 53: 67-72.

Clausen CA and Mattson G (1978), Principles of Industrial Chemistry, Wiley Interscience Publication, New York, p 412.

Dritriev SA, Corner KD and Tsvtkov ON (1961), Synthesis of detergents based on phenols derived from peat oils, Torfyanoya 32: 24-27.

Lebedev NN (1984), Chemistry and Technology of Basic Organic and Petrochemical Synthesis, Mir Publishers, Moscow, p 638. 
Melinikov NN, Baskakov YA and Bokrev KS (1954), Chemistry of Herbicides and Plants Growth Regulators, Gkhi, Moscow, p 38.

Nemetkin SS, Baskahov YA and Melnikov NN (1951), Synthesis of some alkyl and arylalkyl phenoxyacetic acid, Zh. Obsh. Khim 12: 2146-2150. DOI.org/10.1002/ cmdc.200600307

Palma BS, Azim MA, Ismail M, Saha D, Kader MA and Saha $M$ (2007), A mathematical model for the indanylation of $m$-cresol with indene in the presence of benzenesulphonic acid, Bangladesh J. Sci. Ind. Res. 42:1-8. DOI: 10.3329/bjsir.v42i1.349

Saha M, Bhuiyan MSI, Rafique RF and Hasan MM (2006), Indanylation of p-cresol with indene, Dhaka Univ. J. Sci. 54: 121-122. DOI: 10.3329/bjsir.v44i4.4593

Shahruzzaman M, Saha D, Rahman MS and Rahman MS (2015), Application of plackett-burman design to benzylation of $o$-cresol with benzyl alcohol, Bangladesh J. Sci. Ind. Res. 50: 169-180. DOI.org/10.3329/bjsir.v50i3.25580

Saha SK, Saha D and Saha M (2003), Cycloalkylation of p-cresol with cyclooctene, Dhaka Univ. J. Sci. 51: 299-300.
Saha M, Bhuiyan MSI, Rafique RF and Hasan MM and Alam MA (2005), Reaction of phenol with indene in the presence of sulphuric acid, Dhaka Univ. J. Sci. 53: 169-172.

Saha M, Dey HC, Karim MZ, Ismail M and Saha D (2008), Alkylation of cresols with cyclohexene in the presence of $p$-toluenesulphonic acid, Bangladesh J. Sci. Ind. Res. 43: 277-282.

Saha M, Mahmud HMNE, Ghosh SK, Zaman MD, Saha D and Saha SK (2000), Cycloalkylation of $p$-cresol with cycloalkenes in the presence of borontrifluoride etherate, Bangladesh J. Sci. Ind. Res.18: 273-276.

Shahruzzaman M, Alam MA, Sultana S, Robel FN and Saha M (2015), Methylcyclohexylation of phenol: A statistical study, IJESE 8: 628-633.

Starkov SP, Starkova SK, Zhidkova LA and Leonova GS (1972), Orientation during the alkylation of $o$-cresol by olefins on the KU-2 cation exchanger, I.Z.V. Vysoh. Ucheb. Zaved. Khim. Tekhnol. 15: 1186-1189.

Yadav GD and Pala R (2000), Selectivity engineering in the $\mathrm{O}$-versus C-alkylation of $p$-cresol with cyclohexene over sulphated zirconia, Can. J. Chem. Eng. 78: 917-927. 